


\title{
RADIATION-DRIVEN FLAME SPREAD OVER THERMALLY-THICK FUELS IN QUIESCENT MICROGRAVITY ENVIRONMENTS
}

\author{
Linton K. Honda". Youngjin Son" and Paul D. Ronney \\ Department of Aerospace and Mechanical Engincering \\ University of Southern Callitornia. Los Angeles. CA (0)0S9
}

\section{Abstract}

Microgravity experiments on llame spread over thermally thick fucls were conducted using foam fuels 11) obtain low density and thermal conductivity, and thus large spread rate $\left(S_{i}\right)$ compared to dense fuels such as PMMA. This scheme enabled meaningful results to he ohtained even in 2.2 second drop tower experiments. It was found that, in contrast conventional understanding; steady spread can occur over thick luels in quiescent microgravity environments, especially when a radiatively active diluent gas such as $\mathrm{CO}_{2}$ is imployed. This is proposed to be due to radialive iransfer from the flame to the fuel surface. Additionally, the transition from thermally thick to thermally thin hehavior with decreasing bed thickness is demonstrated.

\section{Introduction}

It is well known ${ }^{1.2 .3 .45}$ that convection influences thame spread over solid fuel beds in numerous ways. Flane spread is typically classified as opposed-flow, where the direction of tlame propagation is opposite that of the convective flow past the flame front, or concurrent-How, where convection and spread are in the same direction. Downward flame spread at earth gravity $(1 g)$ is characterized by opposed flow since the unward buoyant flow is opposite the direction of llame spread. whereas upward flame spread is characterized as concurrent flow. At microgravity $(\mu \mathrm{g})$ conditions. where buoyant convection is negligible, flame spread will necessarily be of the opposed-flow variety unless a liorced flow is imposed, because the tlame spreads loward the fresh atmosphere with a self-induced convection velocity equal to the spread rate $\left(S_{1}\right)$. At $\mathrm{lg}$

Graduate Research Assistant. Department of Aerospace and Mechanical Engineering

Graduate Research Assistant, Department of Aerospace and Mechanical Engineering

Professor, Department of Aerospace and Mechanical Engineering, Senior member AIAA

Copyright (C2001 by the Authors. Published by the American Institute of Aeronautics and Astronautics Inc. with permission. self induced convection cin justifiably he ignored since buoyancy-induced llows are of the order of tens of cm/sec. which is much higher than $S_{1}$. however. at $\mu \mathrm{g}$ sell-induced convection obviously cinnor be neglected.

As described by Williams ${ }^{2}$, the basic approach to modeling $S_{i}$ is by equating the heat flux per unit area from the gas phase to the fuel surface $(q)$ to the rate of increase in the enthalpy of the solid fuel, leading to

$$
S_{1}=\frac{q \delta_{:}}{\rho_{r} C_{p . s}\left(T_{s}-T_{m}\right) \tau_{1}}
$$

where $p, C_{p}, T$ and $\tau$ are the density. constant pressure specific heat, temperature. fuel bed thickness and the subscripts $s, g, v$ and $x$ refer to the solid fuel. gasphase, vaporization condition and ambient condition, respectively. $\delta_{\mathrm{g}}$ is the length of the zone over which heat is transterred from the gas to the fuel surface: for opposed-flow flame spread $\delta_{\mathrm{y}}$ is proportional to the convection-diffusion zone thickness $\alpha_{2} J U$ where $\alpha_{p} \equiv$ $\lambda_{g} / \rho_{g} C_{p . g}$ is the thermal diffusivity. $\lambda$ the thermal conductivity and $U$ the opposed flow velocity.

For the simplest case of thame spreald over a thermally-thin fuel bed (in which there is no temperature gradient and thus no conduction within the fuel bed), heat transfer is purely by gas-phase conduction to the fuel bed and thus $q=\lambda_{\mathrm{g}}\left(T_{\mathrm{f}}-T_{v}\right) / \delta_{\mathrm{g}}$. where $T_{f}$ is the flame temperature given by

$$
\begin{aligned}
& T_{1}=\frac{\left(Q_{1}-L_{1}\right) / C_{n .2}+\left(T_{1}-T_{\infty}\right)}{1+S}+T_{\infty} ;
\end{aligned}
$$

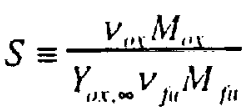

where $Y$ is the mass fraction. $M$ the molecular weight. $v$ the stoichiometric cocfficient. $S$ the stoichiometric oxidant-to-fuel mass ratio. and the subseripts fu and ox refer to solid fuel vapors. and oxidant, respectively. This leads to

$$
S_{j}=A \frac{\lambda_{g}}{\rho_{s} C_{p . s} \tau_{s}} \frac{T_{1}-T_{1}}{T_{v}-T_{\infty}}
$$




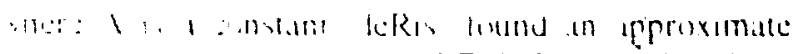

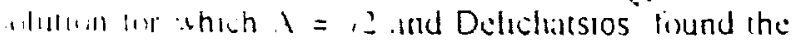

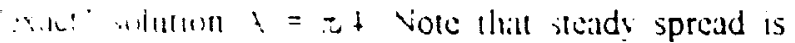

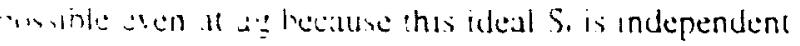

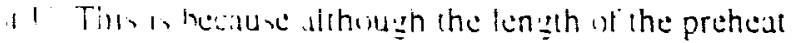

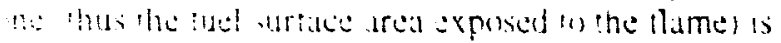

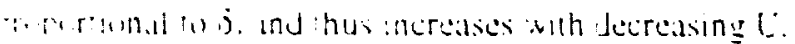
an :mperalure gradient hel ween the ilume and the fucl at a : ilw propormonal so o. thus the heat thux per

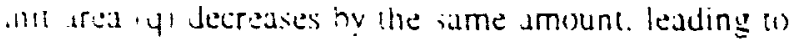
: $)$ aed thange in the wat heal flux whe thel hed.

Fise thermally thin tuels. $i_{i}$ is the ruel hed halthukness. whereas for thermally thick leffectively imi-intinite fuels, where heat conduction through the wlid tuel is important. $\tau_{s}$ is the depth of thermal fenetration into the solid tuel $\left(\mathrm{F}_{\mathrm{p}}\right)$, which can be stimated by equating $q$ to the heat flux within the solid :uel $=\dot{\lambda}_{s}\left\{\left(T_{v}-T_{r}\right) / \tau_{p}\right\}$, where the subscript $y$ refers to the direction normal to the fuel surface:

$$
\tau_{i,}=\frac{\lambda_{1}\left(T_{r}-T_{-}\right)}{q} \Rightarrow S_{1}=\frac{q^{2} \delta_{i}}{\rho_{r} C_{P, 1} \lambda_{v}\left(T_{v}-T_{\infty}\right)^{2}}
$$

This result is identical to that determined by Tarifa and Torralbo and deRis ${ }^{\prime}$ for a prescribed externallyimposed radiative source. so the present approach is considered valid. If heal transter to the fuel bed occurs via conduction and thus $q \approx \lambda_{g}\left(T_{f}-T_{v}\right) / \delta_{g}$ as for thin tuels. the "exact" solution for $S_{i}$ over thick fuels" is sbrained:

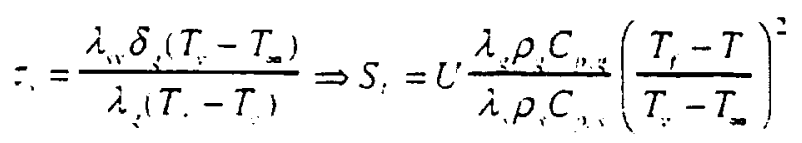

The rransition from thermally thin to thermally:hick hehavior occurs when $\tau_{s} \approx \tau_{p}$. Note then that 1 :iven material may behave as thermally thin or thermally-thick jepending on $\delta_{2}$ and thus $L$.

Euludion 5 shows hat ior hick tuels. $S_{f}-L$ and hus iuggests that $S$, is indeterminate at ug unless a cried llow is dpplied. The conventiondi view". is that

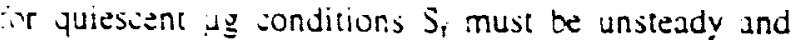
decreasing unal exancion acurs Jue to radiative isses. An analysis' based on unsteady heat conduction is the ruel bed predicts that the thermal penetration Jepth is $-\left(\alpha_{1}\right)^{:}$: which results in $S_{f}-t^{i 2}$. where $t$ is the lime lapse from ignition. Indeed, this scaling indicates that in a sense all tuel beds are thermally thin at $\mu \mathrm{g}$, because $S_{f}$ will always decrease over lime and thus :p will increase until it reaches $\%$. Computations

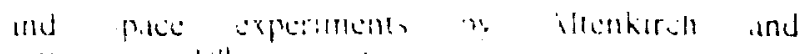

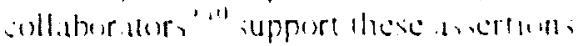

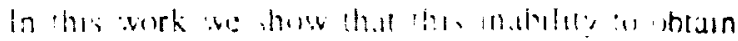

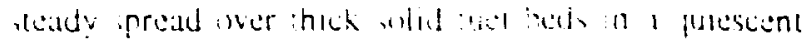

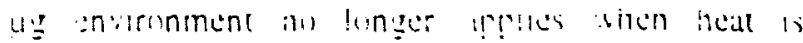

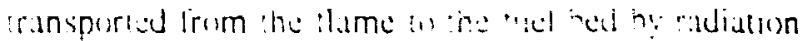

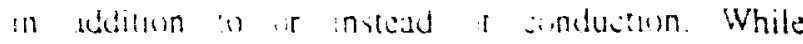

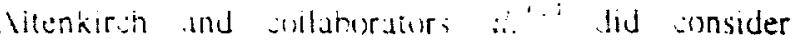

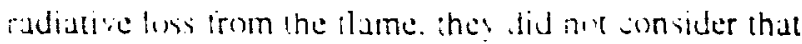
the ridiative transter from the liune to the luet bed could increase the instantaneous 5 . ur lead is iteady ipread. We derive a semi-quanulative prediction for $\xi_{1}$ that is used to motivate $\mu g$ experiments. Which in turn demonstrate the validity of the proposed mecthanisms of thame spread with llame radiation. Additionally. the rransition from thermally thick to thermally-thin behavior is demonstrated as the ruel bed thickness is Jecreased. in a manner consistent with the proposed mechanisms.

ts evidence of the importance of radiative transter from the Mame fron co the tiuel bed, we consult our prior thin-fuel experiments" on the effects of diluent lype (which affects the radiative properties of the atmosphere) on $S_{i}$. Experiments in radiatively inert $N_{2}$, He or Ar diluents showed the conventional behavior where $S_{f}$ is lower and the minimum flammable $\mathrm{O}_{2}$ concentration is higher at $\mu \mathrm{g}$ because $U$ is lower, thus $\delta$ and radiative loss are higher. In contrast. for radiatively active $\mathrm{CO}_{2}$ and $\mathrm{SF}_{6}$ diluents. the opposite behavior is observed. This was attributed to (1) the increased radiative emission from $\mathrm{CO}_{2}$ or $\mathrm{SF}_{6}$, which increases the net heat flux to the tuet bed and 12) reabsorption of this radiation. which reduces the radiative heat loss. (Diluent type also atfects the Lewis numbers of the armosphere but these effects were shown to be of lesser importance.)

\section{Approximate analysis of tlame spread over thick fuels with radiative iransticr}

In this section we present an doproximate model of how tlame-generaled radiacion transmilted to the tuel surface could sifect spread rates tor thick luel beds. When radialive heal :ransier :o the luel bed is signiticant. S. ds glven jy Eqs. : and + are still valid. but Eus. : and $\Sigma$ must be moditied. For lame-generated radiation. $\jmath_{r}$ is supied to the seread process itself, and depends strongly on the sfectral properties of the gas. As a tirst estimate. in this andisis we consider optically thin radiation. where no reabsorgtion xecurs and the spectral properties ian be lumped into a single parameter.

For our estimate of $S$, over thick fuel beds, the tlame front is assumed to be an isothermal volume of optically-thin radiating gas at temperature $T_{1}$ with dimension $\delta_{3}$ in both the directions parallel to and 
perpendicular to the luel hed. We make this choice hecause for optically-thin radiation, there is no length saike lor ritdiation and thus the thermal thickness of the thanc lione conditions is still detemined by the

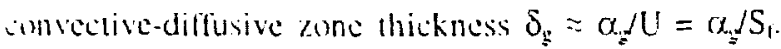
The heal thux per unit area to the luel surtace due wo radiation san then be estimaled as $\Lambda \delta_{\mathrm{g}}$. where $\Lambda=$ toap $\left(\mathrm{T}_{i}^{+}-\mathrm{T}_{v}^{+}\right)$is the radiant heal emission rate per unit colume. $\sigma$ is the Stefan-Boltzman constant and $a_{p}$ is the Planck mean absorption cextficient. The combined clfects of gas-phase radiation and thermal conduction is then given hy $q=\Lambda \delta_{\mathrm{g}}+\lambda_{\mathrm{g}}\left(\mathrm{T}_{\mathrm{f}}-\mathrm{T}_{\mathrm{v}}\right) / \delta_{\mathrm{g}}$. Combining this with $\delta_{1}=0 . / S_{i}$ and Eqs. 4 lead or (assuming unit fuel bed emissivity):

$$
S_{1}=\left[\frac{\Lambda \alpha_{\mathrm{g}}^{2}}{\sqrt{\alpha_{s} \rho_{v} C_{p_{v}, \lambda_{v}}}\left(T_{v}-T_{\mathrm{u}}\right)-\lambda_{s}\left(T_{1}-T_{\mathrm{v}}\right)}\right]^{1 / 2}
$$

This result yields a number of interesting predictions, the most important of which are that without gas-phase radiation, no steady spread is possible $\left(S_{f}=0\right)$ and with gas-phase radiation, $S_{i} \sim \Lambda^{1 / 2}$. Thus. increasing gas-phase radiation should increase $S_{f}$. Of course, the heat loss rate also increases, but the ratio of heat loss to heat generation will remain roughly constant. Equation 6 also shows that pressure effects are important and could increase or decrease $S_{\mathrm{f}}$ since $\Lambda$ $\sim \mathrm{P}$ and $\alpha_{\mathrm{g}} \sim \mathrm{P}^{-1}$

Equation 6 is only valid when the denominator is positive, i.e., when the thick fuel tlame spread parameter $\Gamma \equiv\left(\rho_{g} C_{P, g} \lambda_{g} / \rho_{s} C_{P, s} \lambda_{s}\right)\left(\left(T_{T}-T_{v}\right) /\left(T_{v}-T_{x}\right)\right)^{2}<1$, which is virtually always the case - though for very low density fuels, its value is close to unity. Equation 6 shows that in a given atmosphere $S_{f}$ can be much higher lor fuels with low $\rho_{s} C_{P . s} \lambda_{s}$. This leads us to propose the use of polymeric foams with low $\rho_{\mathrm{s}}$ and $\lambda_{\mathrm{s}}$ to study thick-luel thame spread in short-duration drop tower lests as precursors to space experiments using more quantitiable fuels with larger $\rho_{s} \lambda_{s}$, e.g. PMMA.

A tactor not considered in this discussion is that radiative transfer to the fuel bed will also increase $T_{f}$, as analyzed by deRis', though using representative values of the thermodynamic and transport parameters the predicted effect is not strong enough to affect the above conclusions. It does, however, make the impact of radiative transport slightly stronger than that shown here.

\section{Experimental apparatus}

In order to test for the proposed possibility of steady llame spread over thermally-thick fuels in quiescent $\mu \mathrm{g}$ environments, a set of $\mu \mathrm{g}$ experiments was conducied in the NASA Glenn 2.2 second drop lower ficility, and comparison tests were pertormed in the same apparalus with the same cest comditions at earth gravily.

The experiments were pertimed in rur thame spreald apparalus (Fig. I) lhat hats heen described previously, "so only a brial description is given here, emphasizing the changes made for this study. A 20) liter chamber is lilled with the desired aumosphere by a computer-controlled partial pressure gas mixing system. This chamber is raled for working pressures from vacuum up to 10 atm. The fuel samples are typically 10 $\mathrm{cm}$ wide and $11.5 \mathrm{~cm}$ long and are held between aluminum quenching plales on hoth sides in order to inhibil edge-burning effects. Before each test, a fan inside the vessel is operated to ensure mixing of the components of the atmosphere. Alter allowing lime tor selling of convection currents. the samples are ignited by a 30 gage Kanthal wire wh which 25 VDC is applied. This wire is imbedded in a nitrixilulose membrane that is glued onto the fucl surlixe. For most calses. the samples can be ignited at lg then dropped at an appropriate time so that the $\mu$ g portion of the test would be within the field of view of the cameras, however. some $\mathrm{CO}_{2}$-diluted aumospheres at low $\mathrm{O}_{2}$ concentrations support thame spread only at $\mu \mathrm{g}$, hence in these cases the samples must be ignited at $\mu \mathrm{g}$. The igniter is controlled and the radiometer data (described below) are collected by a microcontroller-based data acquisition and control system.

The tlame-spread process is imaged using two CCD cameras whose signals are connected via fiberoptic cables to ground-based S-VHS video recorders. The video records provide information on the spread rate and tlame shape. One camera is positioned with its viewing axis in the plane of the fuel sample so that it images the tlame front. Another CCD camera is located with its viewing axis orthogonal to the plane of the fuel sample so that it could image laser shearing interferograms of the hames from a side view. In the laser shearing interferometer," the laser beam was expanded and passed through the test section, then reflected off the fiont and rear surfaces of a shearing plate (an optical-quality glass that with parallel faces). By adjusting the beam expander so that the beam is slightly convergent or divergent, an interferogram is obtained. The fringe displacement in the shearing interterogram is proportional to the density gradient rather than density difference between the test image and a reference image as in conventional interferometry. The interferogram was projected on a ground glass screen and recorded via the CCD camera. 


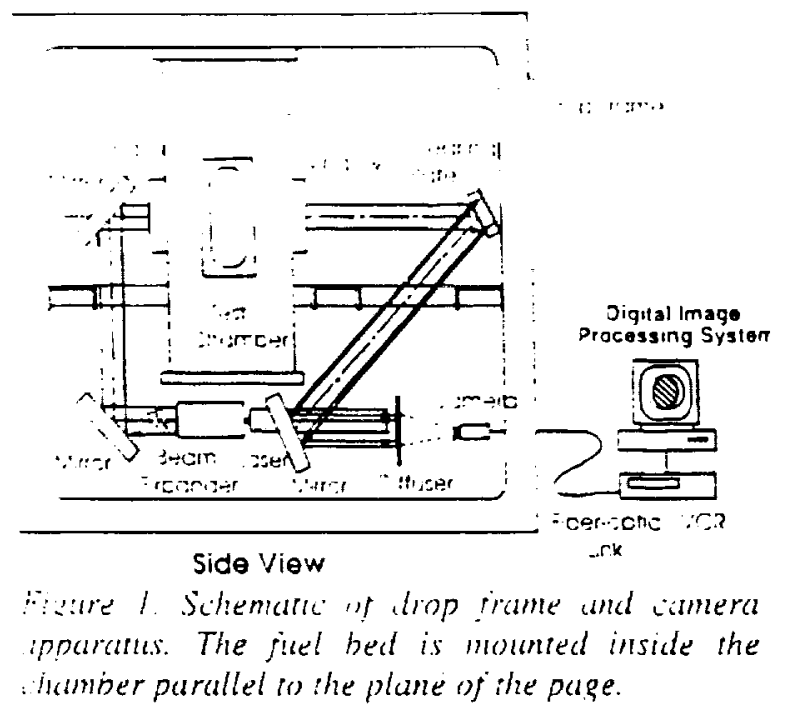

Varrow-angle ivall-mounted thermopile-type radiometers are used to determine the net emission reaching the radiometer alung its line-of-sight, which is an important prediction of the radiation model. Two Iypes of radiometers were used: (1) a tront-side radiometer viewing a hole in the luel bed. which measures unly the gas-phase contribution to the outward radiative flux. and (2) a back-side radiometer that viewing the same hole in the luel bed. which measures the inward gas-phase radiative heat llux.

The standard iuel for fundamental thick-fuel combustion experiments has been poly:nethylmethacrylate (PMMA) which has a thick-fuel oread rate parameter $\lambda_{s}, C_{p},\left(T-T_{0}\right)^{2}$ of about $3.3 \times$ (i) ${ }^{i v} \mathrm{~J}^{2} / \mathrm{m}^{4} \mathrm{~s}$. This relatively large value leads to rather flow rlame spread. e.g about $0.006 \mathrm{~cm} / \mathrm{sec}$ in air at 1 iim. This is iar too low to observe steady-state spread if it exists) in short-duration drop-rower experiments.

What is needed is a thick fuel material for which $\therefore, C_{\text {? }}\left(\mathrm{T}_{1}-\mathrm{T}_{\mathrm{s}}\right)^{\circ}$ is small enough that information might be sbrained in short-duration $\mu \mathrm{g}$ experiments that sult aid in the design of later space experiments using nore readily quantiriahle fuels such ds P.M.M. For this -urgose after evaluating numercus indidate materials. is iave chosen foluphenolic cums shish have values

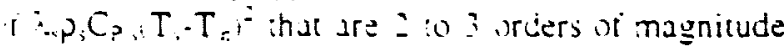
muiler than PMMAt betuluse of the ioams have much (wer :hermal condueivir: in and density $\left(p_{\text {s }}\right)$ than PMIM.t. The polvphenolic oums were shosen primarily reduse the: hase user sooting iendency and רegligible melting or sripping tendency compared to ther toums such as poivilyrene or polyurethane. Of course all coams contain irapped gas, however, the Jensity of the toams we emploved is still at least 20 ume's that of air, so that even if all the trapped gas were air. this air provides a negligible contribution to the overall stoichiometry. The permeability of the foam

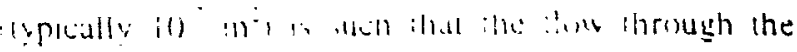
porrous media zan be neglected.

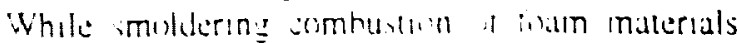

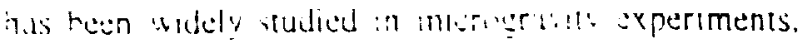

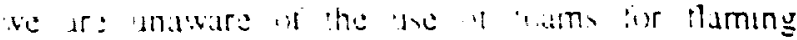

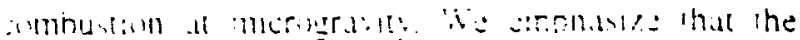

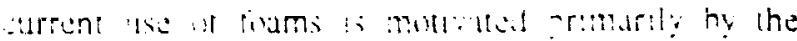
neded an maximize 5 . and ininimise se une xales it

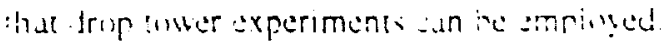

\section{Expermenca! : *ui:}

Figure 2 shows examples il firect images of ipreading thames at lg and ug. From these images the eflect of buovancy ian be jeen. Figure 3 shows examples of the progress of thame spread tflame position vis. time) at l l and $\mu \mathrm{g}$. The slope ot these plots gives the spread rate: a straight line indicates a constant spread rate and thus steady spread. From these tests. it can be seen that that in $\mathrm{O}_{2}-\mathrm{CO}$ : utmospheres. steady tlame spread is possible over thick luels at quiescent $\mu \mathrm{g}$ conditions when gas-phase radiation effects are significant. Figure 4 shows that, as was also seen in the thin tuel tests" ${ }^{\prime \prime}$, for thick fuels the quiescent $\mu \mathrm{g} \mathrm{S}_{\mathrm{f}}$ can be higher than its Ig (downward) counterpart for $\mathrm{CO}_{2}$ diluted atmospheres but not $\mathrm{N}_{3}$-diluted atmospheres. Figure $t$ also shows that, as expected. the spread rate increases with increasing $O_{2}$ concentration. Figure 5 shows that a rather sharp iransition in tlame spread behavior from $S_{f}$ increasing rapidly with pressure to $S_{f}$ nearly independent of pressure is tound at a pressure of about $5 \mathrm{~atm}$. While the cause of this transition is uncertain. it might be due to a transition trom radiation dominated by optically-thin behavior to optically-thick behavior. Moreover, the ug spread rate becomes less dependent on thickness as thickness increases as shown in Fig. 6. This shows the dpproach is a thick ruel regime. The transition thickness is deoul $2 \mathrm{~mm}$ for the case shown. Figure 7 shows that spread rate tecreases with ruel density for these polyphenolic :oams. at least for !arge density. in a manner similar to that predicted by E. 3 ispread rate inversely proportional to density). For imall Jensities. it was cound that the foam behaved in a very difierent beindulur. grimurily jue :o the sormation uf siringy soot sirstures not shown that did

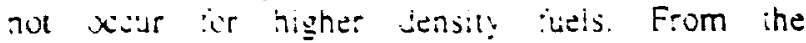
interferometer images shown in Fig. 3 . it an be ieen that, as expected. the tame is ihicker at microgravity than at arrh grawly. ndicating that the lame at microgravily has more iviume and hus an iranster more iadiation io tuel jed. 


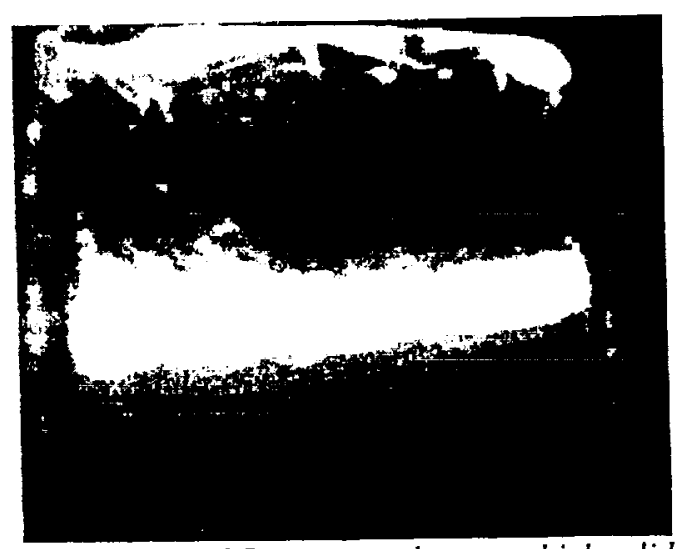

Figure 2. Image of flame spread over a thick solid fuel he't at $\mu \mathrm{g}$. Width of fuel bed is $10 \mathrm{~cm}$. Flame spreads wward the bottom of the inage. Bright band in the lawe' part of the images is the flame front; upper bright band is from the ignition source. (1.) Microgravity.

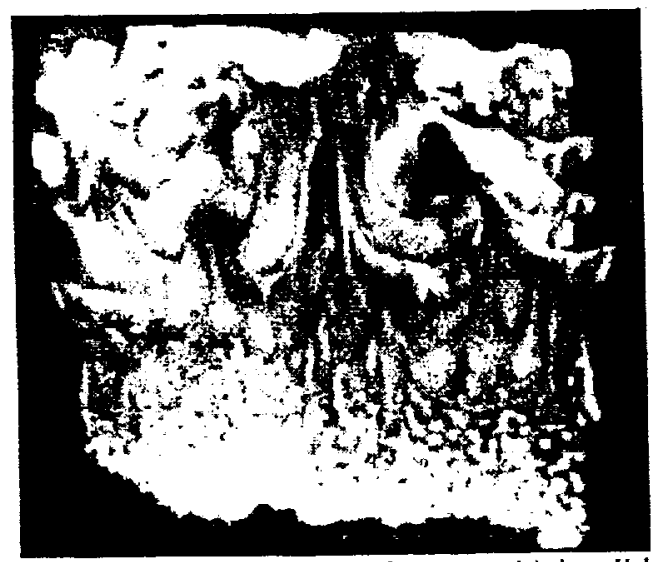

Figure 2. Image of flame spread over a thick solid fuel b'd at $\mu \mathrm{g}$. Flame spreads toward the bottom of the image. (b) Earth gravity.

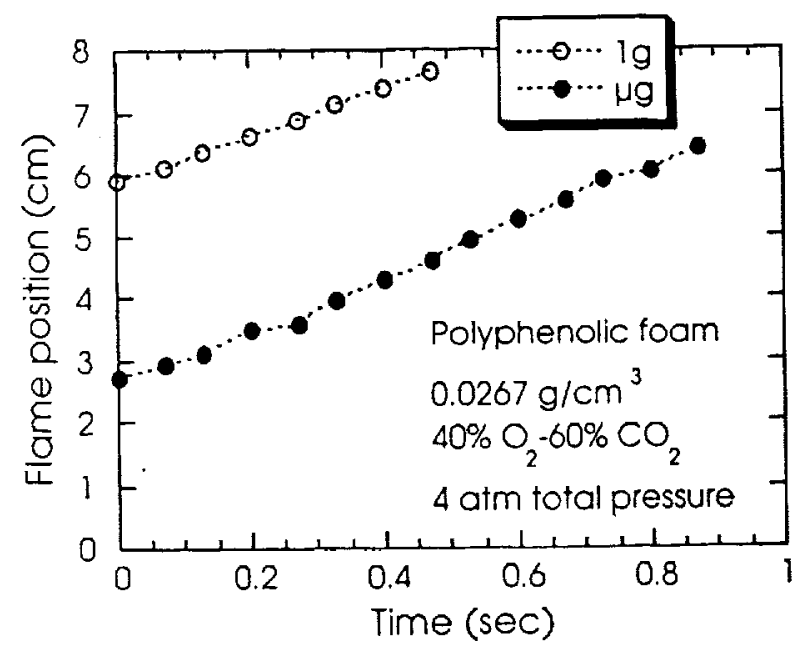

Firsure i. Position of spreading flame as a function of nims.

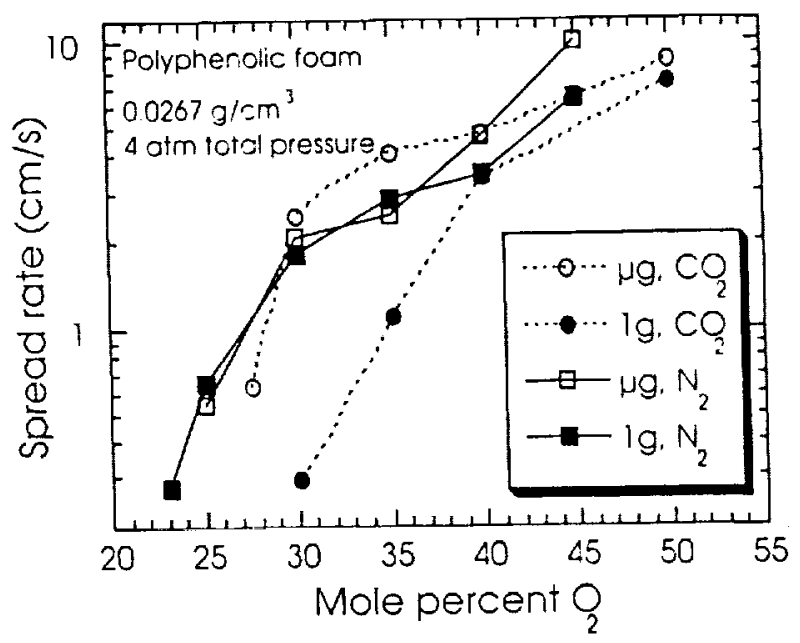

Figure 4. Effect of oxygen concentration on spread rates over thick solid fuel beds at $\mu \mathrm{g}$ and earth gravity.

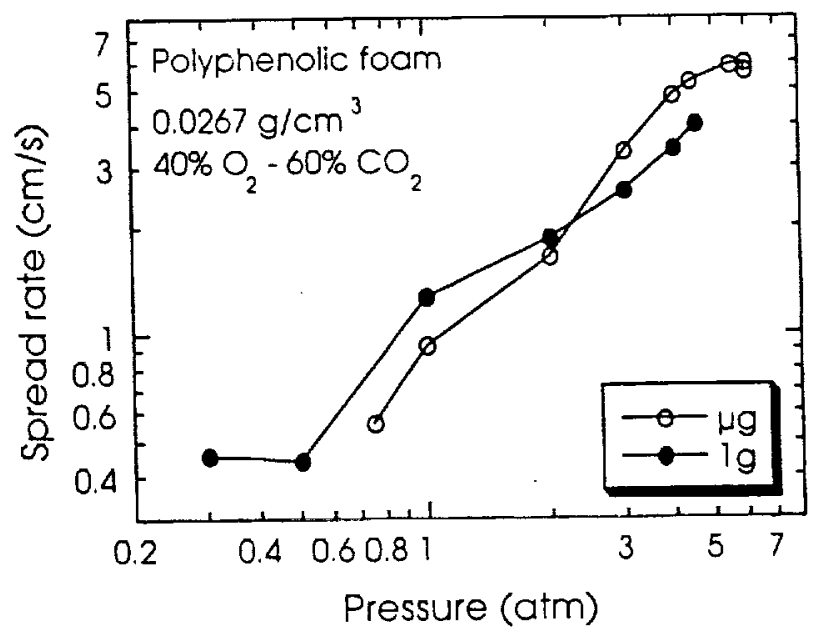

Figure S. Effect of pressure on spread rate over thick solid fuel beds at $\mu \mathrm{g}$ and earth gravity:

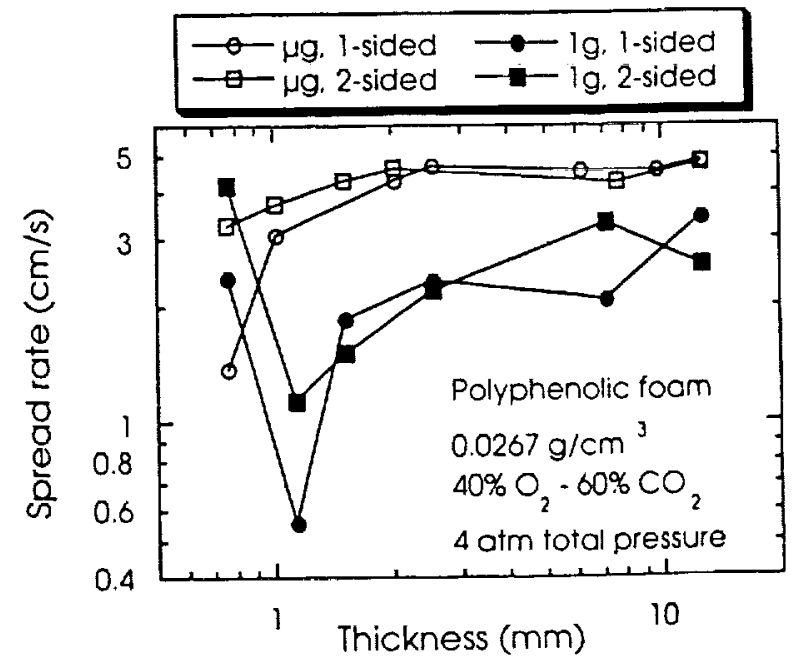

Figure 6. Effect of fuel bed thickness on spread rate over thick solid fuels bed at $\mu g$ and earth gravity. 


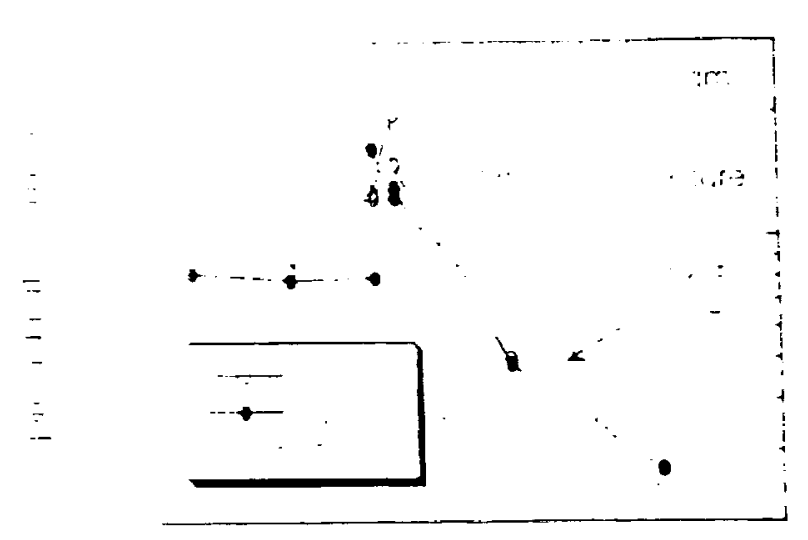

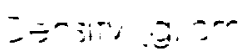

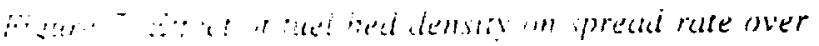

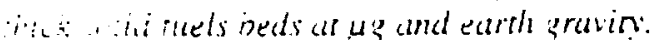

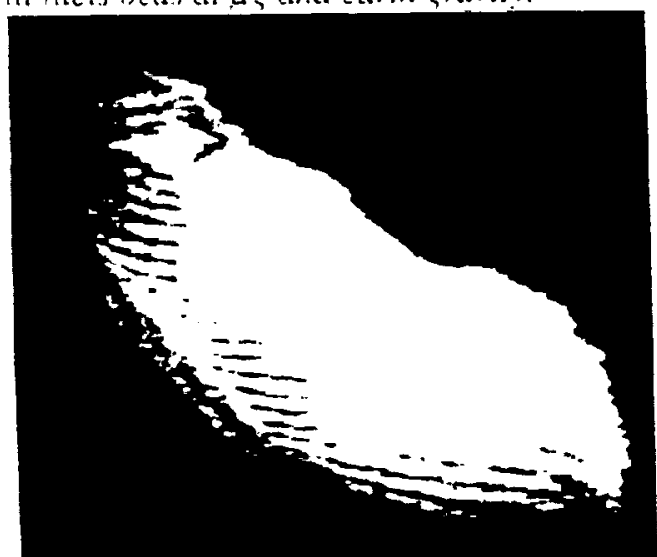

Fir!ure 3. Image of Interferometer from the side of the inci. in: the upper black region represent the thick witume ir the flame. (a) Microgravin:

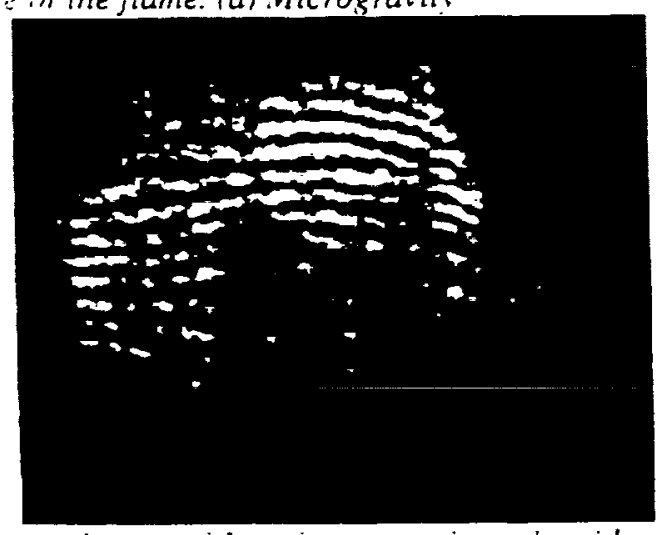

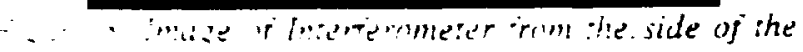

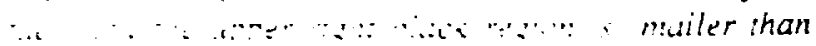

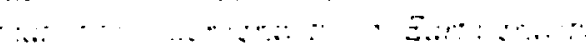

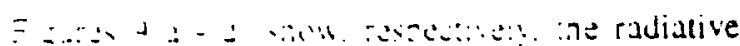

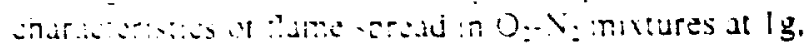

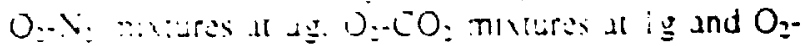

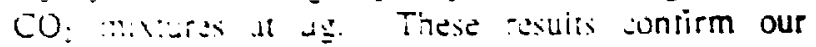

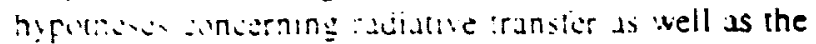

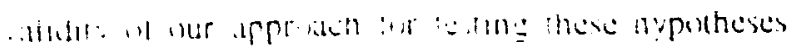

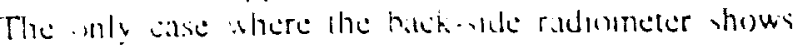

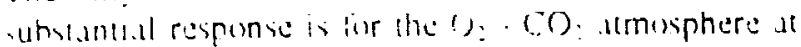
4. The is likely becaluse wi? a the case is thers

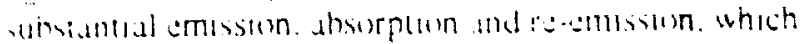

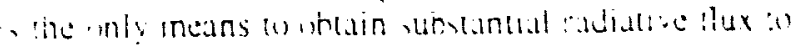

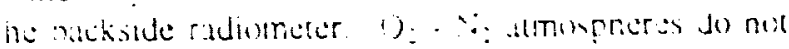

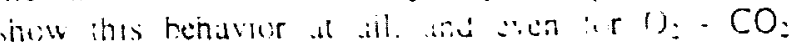
lemupheres his is ieen unly at de where $j$ is larger and thus the ond radialive llus is grealer. This is indewd contirmed in Fig. 9 . which ihows that the peak

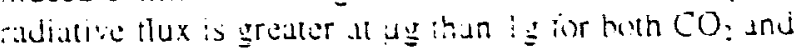
$\therefore$ almospheres.

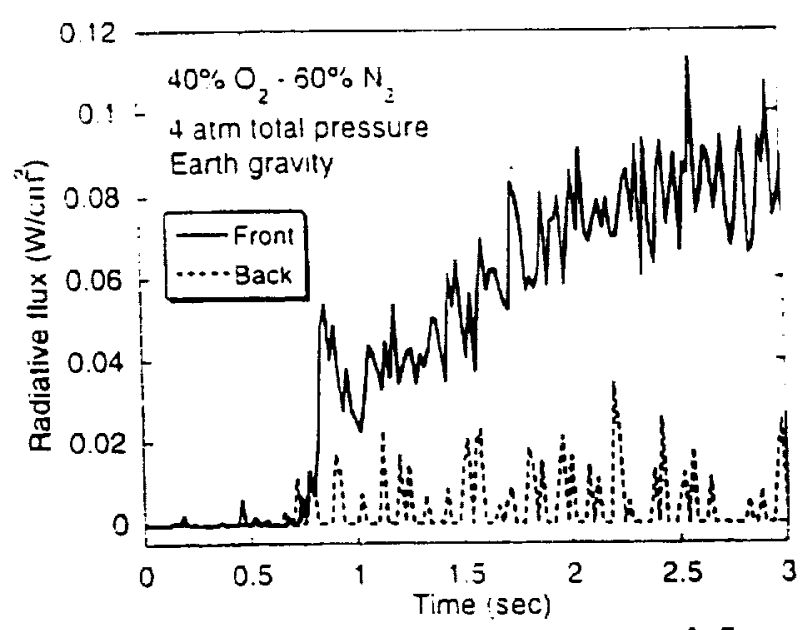

Figure 9. Radiarive flux characieristics of flames spreading over polyphenolic foum ficel. (a) $10 \% \% \mathrm{O}$ :$6090 N_{2}$, earth grawin:

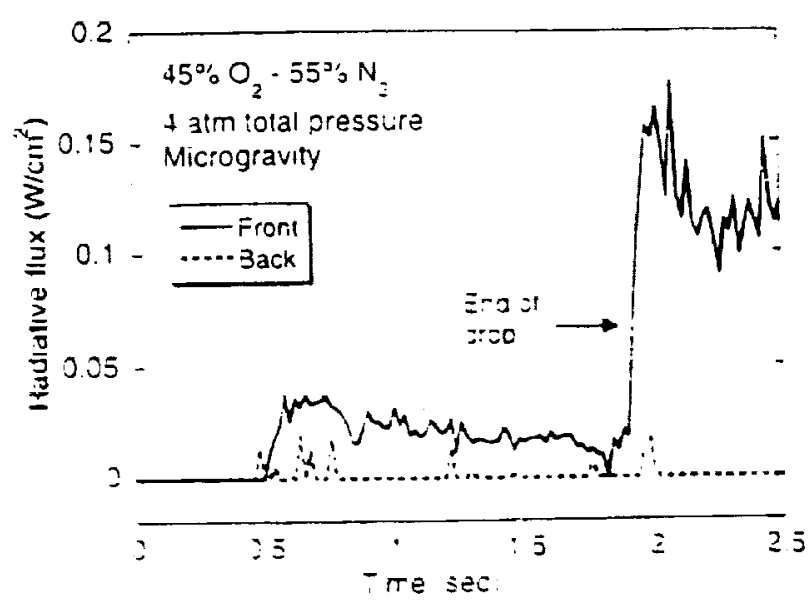

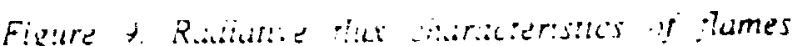

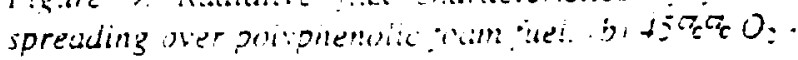
$55 c_{c} V_{2}$ micrograbe: 


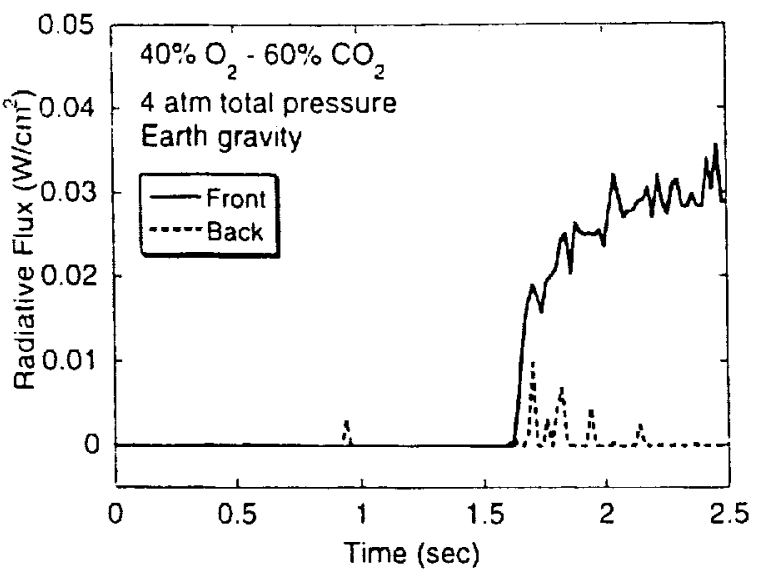

Figure 9. Radiative flux characteristics of flames spreading over polyphenolic foam fuel. (c) $40 \% \% \mathrm{O}_{2}$ $60 \% \mathrm{CO}_{2}$, earth gravity.

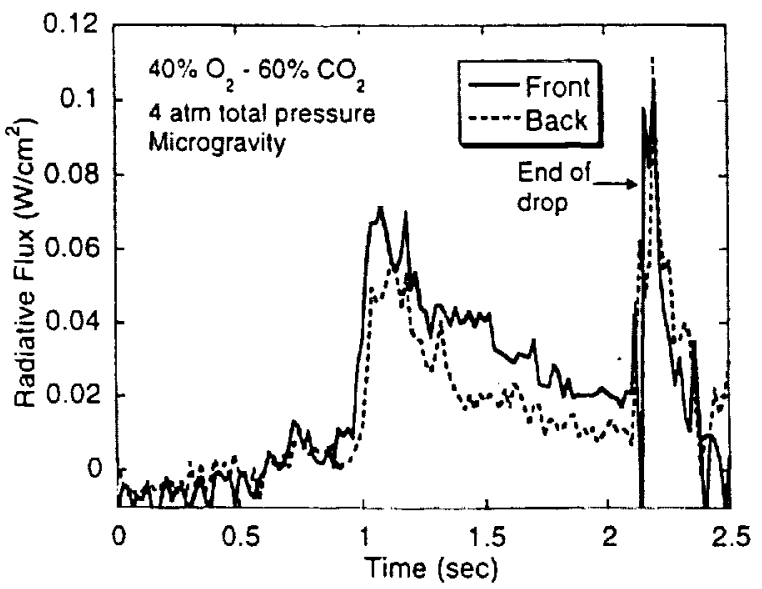

Figure 9. Radiative flux characteristics of flames spreading over polyphenolic foam fuel. (d) $40 \% \% \mathrm{O}_{2}$ $.60 \% \mathrm{CO}_{2}$, microgravity.

\section{Summary and Conclusions}

Microgravity experiments on flame spread over thermally thick fuels were conducted using foam fuels to obtain low density and thermal conductivity, and thus large spread rate $\left(S_{f}\right)$ compared to dense fuels such as PMMA. This scheme enabled meaningful results to be obtained even in 2.2 second drop tower experiments. It was found that, in contrast conventional understanding, steady spread could occur over thick fuels in quiescent microgravity environments, especially when a radiatively active diluent gas such as $\mathrm{CO}_{2}$ is employed. In some cases with $\mathrm{CO}_{2}$ diluent the spread rate was actually higher at $\mu \mathrm{g}$ than at $\mathrm{lg}$ despite the absence of convection at $\mu \mathrm{g}$, which without radiative transfer is expected to preclude the possibility of steady spread. This was shown to be due to radiative transfer from the flame to the fuel surface. This assertion is consistent with measurements of the radiatively fluxes 10 and from the fuel bed. This conclusion was also supported by intertierometer images showing that the thames where much thicker at $\mu \mathrm{g}$ than Ig, indicating that the $\mu \mathrm{g}$ hames can radiate more heat to the fuel bed even to the point of overwhelming the conductive heat flux. Additionally, the transition from thermally thick to thermally thin behavior with decreasing bed thickness was demonstrated, at a typical luel bed thickness of $2 \mathrm{~mm}$.

These results are relevant to studies of fire safety in manned spacecraft, particularly the International Space Station that uses $\mathrm{CO}_{2}$ lire extinguishers. $\mathrm{CO}_{2}$ may not be as effective as an extinguishing agent at microgravity as it is at earth gravity in some conditions because of the differences in spread mechanisms between the two cases. In particular, the difference between conduction-dominated heat transport to the fuel bed at Ig vs. radiation-dominated heat transport at $\mu \mathrm{g}$ indicates that radiatively-inert diluents such as helium could be preferable in $\mu g$ applications.

\section{Acknowledgments}

This work was supported by the NASA Glenn Research Center under grants NAG3-1611 and NCC3671 . The authors are grateful to our grant monitors. Drs. Sandra Olson and Suleyman Gokoglu, for many helpful discussions and technical support. We also thank the FEANICS team and the NASA-Glenn 2.2-second drop tower support staff for their help in coordinating and supporting the $\mu \mathrm{g}$ experiments.

\section{References}

' deRis, J. N. "Spread of a laminar diffusion tlame," Twelfth Symposium (International) on Combustion, The Combustion Institule, Pittsburgh, 1969. p.241.

$?$ Williams, F.A. "Mechanisms of Fire Spread," Sixteenth Symposium (International) on Combustion, The Combustion Institute, 1976, p. 1281.

${ }^{3}$ Fernandez-Pello, A. C., and Mao, C. P. "A Unified Analysis of Concurrent Modes of Flame Spread," Combust. Sci. Tech., 1981, 26, pp.147-156.

4 Fernandez-Pello, A. C. "Flame Spread Modeling," Combustion and Flame, 1984, 30, pp.119-135.

$\$$ Wichman, I. S. "Theory of Opposed-Flow Flame Spread," Prog. Energy Combust. Sci., 1992, Vol.18. pp. 553-593.

${ }^{6}$ Altenkirch, R.A., Eichorn, R., Shang, P.C. "Buoyancy Effects on Flames Spreading Down Thermally Thin Fuels," Combust. Flame., 1980, 37, p.71.

7 Delichatsios, M. A. "Exact solution for the Rate of Creeping Flame Spread over Thermally Thin Materials," Combust. Sci. Tech., 1986, 44, pp. 257-267. 


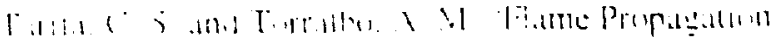

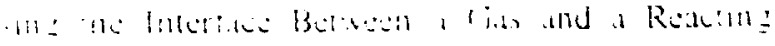

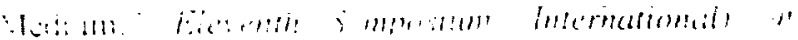

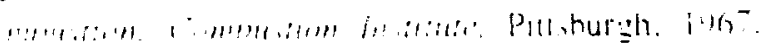

Honda. L. K. and Ronney. P. D. . Elfects of Ambient himinphere in Flame Spread at Microgravity." Gimburam Sotence and Technologer 1998. Vol 13:. ר? $267-291$

Liu. 3. B.. Runney. P. D. "Moditied Fourier Transfirm Wethod for Incerterogram Fringe Pattern Anulysis." Applied Optics. Vol, 36. 1997. pp. 6231 $n=41$.
} 